\title{
Self-assembly of heterogeneous supramolecular structures with uniaxial anisotropy
}

M. Ruiz-Os'es, ${ }^{1}$ N. Gonz'alez-Lakunza, ${ }^{2}$ I. Silanes, ${ }^{3}$ A. Gourdon, ${ }^{4}$ A. Arnau, ${ }^{5,2}$ and J. E. Ortega ${ }^{5,6}$

SUPPORTING INFORMATION
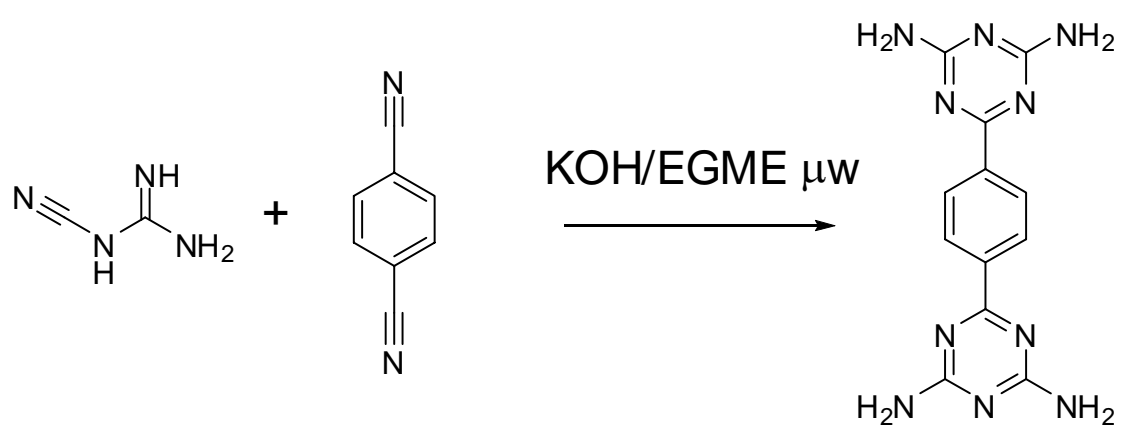

\section{General}

NMR spectra were recorder on a Bruker Avance 300 in DMSO d6 solutions at $20^{\circ} \mathrm{C}$ and internal standart: $\delta \mathrm{H}: 2.50 \mathrm{ppm}$ and $\delta \mathrm{C}: 39.43 \mathrm{ppm}$. Mass Spectroscopy was performed with a MS/MS API-365 (Perkin Elmer Sciex). Elemental analyses were done by the Service d'Analyse de l'ICSN (Paris). The microwave heating was carried out in closed vials with a CEM-Discover monomode microwave apparatus at 300 watts under the conditions (temperature, time) given here. After completion of the reaction, the vessel was cooled down rapidly to $60^{\circ} \mathrm{C}$.

\section{Synthesis}

Powdered potassium hydroxide (20 mg, $0.35 \mathrm{mmol}$ ) was added to dicyandiamide (168.2 $\mathrm{mg}$, $2 \mathrm{mmol}$ )), terephthalonitrile (128.1 mg, $2 \mathrm{mmol}$ )in $3 \mathrm{ml}$ of ethyleneglycol monomethylether. The mixture was then heated under microwave radiation for $10 \mathrm{mn}$ at $190^{\circ} \mathrm{C}$, then cooled to RT, suspended in boiling water $(10 \mathrm{mn})$, hot filtered and the washed with methanol (2x $20 \mathrm{ml})$ and acetone (2 x 10ml). Yield: $80 \%$.

MS (ES): $297(\mathrm{MH}+)$

${ }^{1} \mathrm{H}$ NMR (300MHz, DMDO-d $\left.\mathrm{d}^{6}\right): \delta=8.32$ (s, 4H, arom), 6.81 (br s, 8H, $\mathrm{NH}_{2}$ ).

${ }^{13} \mathrm{C}$ NMR (75.5 MHz, DMSO-d $\left.{ }^{6}\right): \delta=169.7,167.3,139.4,127.38$ ppm.

Anal. Calcd. or $\mathrm{C}_{12} \mathrm{H}_{12} \mathrm{~N}_{10}$ (296.29): C, 48.64; H, 4.08; Found: C,49.0; H, 3.9. 